\title{
ARTIGO
}

\section{TELEVISÃO EDUCATIVA DO INSTITUTO DE EDUCACÃO DO ESTADO DA GUANABARA: TELE-EDUCAÇÃO PARA O MAGISTÉRIO (1960 - 1975)}

Cíntia Nascimento de Oliveira Conceição* Pontifícia Universidade Católica do Rio de Janeiro (PUC-Rio), Rio de Janeiro - RJ, Brasil

RESUMO: Este artigo tem o objetivo de analisar a experiência da televisão educativa do Instituto de Educação do Estado da Guanabara (1960 -1975), destacando os cursos de formação de professores para televisão, que foram responsáveis pela construção do modelo de audiovisual educativo praticado nos anos iniciais da televisão. A proposta do Instituto era oferecer conteúdo teórico e técnico ao professor, dando-lhe condições de atuar como produtor responsável por todas as etapas de um programa televisivo. O Instituto atuou tanto no sistema aberto quanto no fechado de TV e tinha como objetivo conquistar uma audiência diversificada, com programas para família, cursos supletivos e de especialização. O formato de televisão educativa praticado no Instituto agregava interesses comerciais e educativos. A pesquisa foi feita com periódicos da época e documentos do Centro de Memória Institucional do Instituto de Educação do Rio de Janeiro.

Palavras-chave: Televisão Educativa. Estado da Guanabara. Formação de Professores. História da Educação.

\section{EDUCATIONAL TELEVISION OF THE EDUCATION INSTITUTE OF GUANABARA STATE: TELE. EDUCATION FOR TEACHING $(1960$ - 1975)}

ABSTRACT:This article aims to analyze the experience of educational television of Education Institute of Guanabara State (1960 -1975), highlighting the training courses of teachers for television, who were responsible for the construction of educational audiovisual model practiced in the early television in Brazil. The Institute's proposal was to provide theoretical and technical content to the teacher, giving him the conditions of acting as a producer responsible for all stages of a television program. The Institute has worked both in the open and closed TV system and aimed to achieve a diversified audience, with programs for family, supplementary courses and professional specialization. The educational television format performed in the Institute had the goal of adding commercial and educational interests.

\footnotetext{
“Doutora em Ciências Humanas Educação pela Pontifícia Universidade Católica do Rio de Janeiro (PUC-Rio). Pesquisadora do Grupo de Pesquisa Educação, História e Comunicação (PUC-Rio). E-mail: $<$ cintiadeoliveira@yahoo.com.br > .
} 
The research have used old newspapers and documents of Institutional Memory Center of the Rio de Janeiro Institute of Education.

Keywords: Educational Television. State of Guanabara. Teacher Education. History of Education.

\section{INTRODUÇÃO}

A primeira emissora de televisão brasileira foi a TV Tupi, inaugurada no dia 18 de setembro de 1950, em São Paulo, como parte integrante dos Diários Associados ${ }^{1}$, grupo de empresas de comunicação dirigido por Assis Chateaubriand. A TV Tupi também foi pioneira na América Latina, situando o Brasil como um dos primeiros países a ter uma emissora de televisão. Antes, apenas Inglaterra, Estados Unidos, França, Alemanha e Holanda possuíam programação televisiva. A televisão chegou ao Brasil no período em que o rádio era o veículo de comunicação mais popular do país, com abrangência quase nacional, alcançando famílias nos centros urbanos e nas áreas rurais. Diferente do rádio, que inicialmente pautou a programação com base na cultura e na educação, a TV nasce com propósitos comerciais, com o objetivo de ampliar o consumo de bens e de serviços pela via da informação de notícias do cotidiano e do entretenimento.

Segundo Jambeiro (2002), o rádio influenciou o padrão da TV brasileira porque os meios de comunicação de massa no Brasil sempre foram controlados e operados por interesses privados. O Estado apenas regulamentava os serviços. Os custos de manutenção eram oriundos da venda de anúncios ou mantidos por patrocinadores, contudo, jamais se distanciaram do governo. Percebemos que as despesas para manutenção representaram um obstáculo para criação de uma TV pública nos moldes da BBC inglesa ou da PBS norte-americana que são financiadas com o dinheiro do contribuinte e sua programação não é cerceada pelo governo. As emissoras de TV brasileiras eram completamente dependentes do mercado publicitário e, portanto precisavam de audiências cativas para sua programação. "Duas características são marcantes na programação inicial da TV brasileira: a herança radiofônica e a subordinação total dos programas aos interesses e estratégias dos patrocinadores" (PRIOLLI, 1985, p. 23). Apesar da dependência comercial, desde o início a TV foi estruturada a partir da legislação de radiodifusão como uma concessão pública autorizada pelo governo federal que deveria estar em consonância com os objetivos políticos e educacionais do país.

Em novembro 1960, com o decreto 49.259 foi instituída a Campanha Nacional de Radiodifusão Educativa (C.N.R.E.), a cargo do Serviço de Radiodifusão Educativa (S.R.E.) e diretamente 
subordinada ao Ministro de Estado da Educação e Cultura. O objetivo era promover a irradiação de programas científicos, literários e artísticos de caráter educativo; informar e esclarecer, quanto à política de educação do país; orientar a radiodifusão como meio auxiliar de educação e ensino; incrementar o intercâmbio de programas culturais com outras emissoras do país e do estrangeiro; estimular a educação musical do povo em suas diferentes formas de manifestação; promover e patrocinar a gravação de obras musicais e literárias de autores brasileiros, destinadas à documentação e divulgação.

No mesmo período, a UNESCO liderou uma campanha em prol do ensino a distância via rádio e televisão nos países em desenvolvimento. Para isso, organizou vários congressos internacionais para discutir o tema junto a especialistas em comunicação de massa, pedagogos, políticos, acadêmicos e artistas. Em 1962, o Instituto de Educação do Estado da Guanabara ${ }^{2}$ organizou o seminário Televisão Educativa, ministrado pelo professor Armand Hunter, da Michigan State University, nos dias 28, 29 e 30 de agosto. Posteriormente, em 1967, com o lançamento do $1^{\circ}$ Centro Experimental de Televisão Educativa no Estado da Guanabara, sediado no Instituto de Educação, a formação de professores e técnicos para produção, operação e direção para programas educativos ganhou destaque. As professoras Alfredina de Paiva e Souza e Judite Brito de Paiva e Souza eram as coordenadoras do curso que recebeu alunos de diferentes regiões do país.

Havia uma pressão internacional, liderada pela UNESCO, para o uso da TV em projetos educacionais nos países em desenvolvimento. Vivíamos um processo acelerado de industrialização e o país necessitava de mão de obra qualificada (JAMBEIRO, 2002, p. 120). O modelo de educação proposto pela UNESCO era o da alfabetização funcional visando, sobretudo, o mercado de trabalho. Esse modelo foi adotado no Brasil.

Segundo Cunha (1975) o cenário político educacional do período indicava uma política de contenção para níveis mais elevados de escolarização e renda - com a reforma universitária de 1968 - e uma política de liberação para os grupos menos escolarizados e de baixa renda. A tele-educação fez parte dessa política de liberação de alfabetização para as massas direcionada aos adolescentes, pré-adolescentes e adultos, bem como, a extensão da escolaridade mínima obrigatória de 4 para 8 anos. "A alfabetização de grandes massas de trabalhadores terá a função econômica de unificar, em termos de posse de um requisito educacional, a oferta de força de trabalho, incorporando ao mercado urbano as massas rurais" (p. 286).

A experiência do Instituto de Educação com a produção televisiva deixou pouca memória. Encontramos vestígios desta iniciativa, 
na realização de pesquisa sobre a tele-educação no Estado da Guanabara e sobre a telenovela educativa João da Silva $a^{3}$. Nesse percurso pesquisei o trabalho desenvolvido pela professora do Instituto de Educação Alfredina de Paiva Souza que junto a outros educadores foi uma das responsáveis pela formatação artística e ideológica da TV educativa do período, bem como dos rumos que a formação escolar deveria seguir para lidar com o novo veículo de comunicação de massa: a televisão.

Nos acervos impressos de leituras sobre história da televisão há uma lacuna sobre a experiência da TV com a educação formal. É comum reconhecermos o caráter educativo da TV principalmente quando nos referimos aos hábitos culturais e ao comportamento dos telespectadores, porém a relação com a educação formal ainda é pouco discutida. Estamos falando de uma história recente da televisão brasileira, que por diferentes motivos está esquecida. Um dos problemas encontrados ao estudarmos a televisão é a dificuldade de localização e acesso aos acervos. Muitos documentos estão em posse de familiares de artistas e produtores da época e outros ficaram restritos às emissoras de TV que se responsabilizam pela conservação e utilização do acervo e, ao mesmo tempo, dificultam o acesso à pesquisa.

O objetivo deste artigo é analisar a experiência da televisão educativa do Instituto de Educação do Estado da Guanabara (1960 -1975), destacando os cursos de formação de professores para televisão, que foram responsáveis pela construção do modelo de audiovisual educativo praticado nos anos iniciais da televisão. Trabalhamos a partir das concepções da nova história, cuja base filosófica se apoia na ideia de que a realidade é social e culturalmente construída.

Segundo Burke (1992), os historiadores tradicionais definem a história como uma narrativa dos acontecimentos seguindo o paradigma tradicional de que a escrita da história deveria ser baseada em documentos oficiais. A nova história destaca a análise das estruturas buscando outros tipos de evidências que trazem à tona, histórias do cotidiano e de grupos subalternos. Os registros oficiais preservam geralmente o ponto de vista governamental e dos grupos com influência social e econômica. A reconstrução das histórias dos grupos subalternos necessita de outras fontes. (Burke, 1992, p. 24).

Para esse a realização desse artigo, alicerçado nos pressupostos da nova história, utilizamos impressos comerciais veiculados no período de 1960 a 1975. O período escolhido foi marcado por muitas transformações na sociedade brasileira como a ditadura civil-militar de $1964^{4}$ e a consolidação da televisão como veículo de massa. A história da tele-educação no Estado da Guanabara possui poucos registros e a maioria dos audiovisuais educativos do período 
se perdeu porque a programação era realizada ao vivo. Os poucos registros audiovisuais que restaram se perderam por falta de interesse do poder público e por falta de armazenamento adequado. No início da TV a programação era ao vivo e o registro da programação era realizado por documentos impressos. A inserção do videotape nos anos 1960, não garantiu a preservação da programação porque as fitas eram reaproveitadas para diminuir os custos de produção. Não existia interesse em arquivar esses audiovisuais.

A pesquisa histórica sobre tele-educação na Guanabara foi realizada com fragmentos de diferentes tipos de documentos: oficiais, fotografias, textos sobre tele-educação preservados por familiares de pioneiros como Gilson Amado e Lourival Marques e reportagens de jornais e revistas. Utilizamos documentos da Hemeroteca Digital Brasileira para a consulta de periódicos veiculados durante os anos de 1960 até 1975 , arquivos digitalizados do jornal O Globo, disponibilizados para assinantes, e recortes de jornais e revistas preservados nos arquivos pessoais da família de Gilson Amado. Também pesquisamos no Centro de Memória Institucional do Instituto de Educação - CEMI, organizado pela professora Heloisa Helena Meirelles dos Santos.

Neste artigo, escolhemos a análise de conteúdo, reconhecendo-a como um procedimento de pesquisa, "no âmbito de uma abordagem metodológica crítica e epistemologicamente apoiada numa concepsão de ciência que reconbece o papel ativo do sujeito na produção de conbecimento" (FRANCO, 2008, p. 10). O corpus documental utilizado nesse texto é formado por cadernos e colunas sobre educação e televisão, publicados nos impressos comerciais: Correio da Manhã, Diário de Notícias, Jornal do Brasil, O Globo e Revista do Rádio. E também documentos do acervo do CEMI. O impresso comercial tem intencionalidades diversas. A sua função é informar, entreter e vender os produtos e serviços dos anunciantes. Existe uma relação de dependência com os leitores e anunciantes.

O documento histórico originário da imprensa comercial não deve ser absorvido como reflexo da realidade porque ele representa um recorte do real definido por grupos específicos: jornalistas, intelectuais, artistas. Segundo Capelato (1988), o jornal não é um transmissor imparcial e neutro dos acontecimentos e também não é uma fonte desprezível porque é permeada pela subjetividade. A vida cotidiana, registrada em diferentes aspectos nos jornais, permite a compreensão e análise dos ideais dos nossos antepassados ilustres ou anônimos.

Os espaços dos meios de comunicação são os grandes responsáveis pelos processos de sociabilidade e, em especial, como promotores do debate público sobre temas de interesse comum, entre eles a memória. Partimos do pressuposto que a história é constituída 
pela experiência humana em sociedade, em uma constante disputa de ideias e de memórias coletivas, individuais, das classes dominantes e das classes dominadas. Percebemos que houve um apagamento da memória de algumas experiências educacionais com televisão nos anos de 1960 e 1970. Seja pelo caráter popularesco e de entretenimento da televisão ou pelo período turbulento da ditadura civil-militar que afligia o país, a história da televisão educativa no Brasil ficou em segundo plano.

\section{A TELEVISÃO NO INSTITUTO DE EDUCAÇÃO DO ESTADO DA GUANABARA}

Para oferecer cursos de formação sobre televisão educativa, o Instituto de Educação constituiu o $1^{\circ}$ Centro Experimental de Produção e Treinamento de Pessoal para a Televisão Educativa, em 1967, o que lhe valeu um convênio com a Fundação Centro Brasileiro de Televisão Educativa (FCBTVE) para atuar em âmbito nacional. O centro tinha dois estúdios com equipamentos profissionais e uma sala de controle técnico. Os cursos oferecidos no Instituto receberam professores de diferentes partes do Brasil e alguns programas produzidos por estes alunos foram exibidos em âmbito nacional com convênio da FCBTVE. Durante os anos 1970 e 1971, o Instituto de Educação fez convênio para transmissão de programas educacionais com uma emissora comercial de TV do Rio de Janeiro, a TV Continental, Canal 9. A programação era exibida em horário nobre, das 19 às 21 horas de segunda a sexta-feira.

A TV educativa no Brasil era dividida em dois sistemas de circuito: aberto e fechado. No circuito fechado as transmissões eram feitas por cabos para um local especifico, a área de abrangência era pequena, às vezes restrita a apenas uma instituição. No sistema de circuito aberto a transmissão era feita por radioeletricidade com capacidade de transmissão do sinal a longa distância. Essa divisão em dois sistemas aberto e fechado favorecia a necessidade de manter o controle pedagógico das produções televisivas. Se por um lado havia interesse em uma TV educativa direcionada à alta cultura e à divulgação científica, por outro se clamava por modelo didático, sistematizado pedagogicamente para suprir o currículo escolar, e ainda havia pressões para um modelo que agregasse a cultura popular, a instrução, o conteúdo supletivo e o entretenimento. As peculiaridades dos dois sistemas serviram para definir estratégias de formação de audiências, permitindo o monitoramento da programação.

O Instituto de Educação do Estado da Guanabara atuou nos dois sistemas ${ }^{5}$. Neste período, duas concepções de TV educativa serviram de parâmetros para os educadores brasileiros: a proposta 
da $\mathrm{BBC}$, rede europeia que sinalizava para um perfil independente financiado pela população e com programação definida por diferentes setores da sociedade (universidades, museus, bibliotecas), geralmente identificados com a alta cultura; e a proposta da UNESCO que congregava valores populares a um ideal educativo globalizado que deveria estar de acordo com princípios internacionais de alfabetização de adultos e de formação profissional. A televisão educativa do Instituto operava orientada pelas duas concepções, porém a proposta direcionada ao ensino a distância e a necessidade de aumentar os índices de alfabetizados no país encontrava maior acolhimento. Uma programação estruturada na alta cultura demandava audiências com índices altos de escolarização, de leitura e de acesso a bens culturais diversificados. No Brasil, a televisão educativa foi criada empenhada na diminuição dos índices de analfabetismo de jovens e adultos.

\section{PROGRAMAC̦ÃOEAUDIÊNCIA:INSTITUTODEEDUCAC̦ÃOENTREOCOMERCIALEOEDUCATIVO}

A televisão como meio de comunicação de massa está intrinsecamente vinculada às características de um produto cujo objetivo é o sucesso comercial, que, em outras palavras, quer dizer acesso ao maior número possível de telespectadores, vistos como consumidores dos produtos e ideias veiculados na programação. Mesmo quando nos referimos à televisão educativa e não comercial, o sucesso de sua programação será avaliado pela audiência. Logo, pensar o direcionamento da programação educativa é também uma forma de manter o controle sobre o público escolhido, oferecendo produtos capazes de satisfazê-lo.

Nos anos de 1960, o modo de fazer televisão se consolidou tendo como alvo principal a família. A televisão brasileira, e principalmente no Rio de Janeiro, se consolida com base na ideia de que "o fazer televisão" é fazer programas "ajustados à rotina de horários de trabalho e de lazer de uma casa". Daí que o "público" por excelência da televisão é a "família" (BERGAMO, 2010, p. 64). As emissoras comerciais passaram a definir a grade de programação tendo como referência os membros da família. Foi também um período em que a programação recebeu críticas por ser muito popular, ou seja, priorizar os demais programas de entretenimento, que eram de fato os mais assistidos da televisão brasileira. Foi criada uma campanha contra o grotesco na televisão liderada pelo colunista do jornal Ultima Hora, Eli Halfoun, em 1968, defendendo uma televisão sadia, sem atrações que apelasse a boa fé da audiência ou optasse pelo sensacionalismo (RIBEIRO \& SACRAMENTO, 2010, p. 112).

Nesse contexto de crítica ao baixo nível da programação, a formação realizada no Instituto de Educação seguia parâmetros de 
revitalização da televisão, baseados no conceito de horizontalidade e verticalidade ${ }^{6}$ utilizado pela TV Excelsior, em que as faixas de horário eram definidas da seguinte forma: manhã, programas infantis; tarde, programas femininos; noite, o horário nobre com noticiários, telenovelas e programas de auditório.

Apesar de ter o foco na televisão educativa e defender a necessidade de uma televisão pública, o Instituto de Educação apostava em técnicas modernas de fazer televisão e o parâmetro brasileiro que existia era o da televisão comercial. Assim, investir na formação dos alunos, para a preparação de conteúdos femininos de interesse público, era uma maneira de mostrar que o educativo e, principalmente, a presença do educador, era fundamental na elaboração de temas para a televisão. Segundo Alfredina de Paiva e Souza (1969), os programas de radiodifusão educativa deveriam se inserir nos interesses e vivências das audiências ${ }^{7}$, e por isso os professores precisavam conhecer profundamente a "linguagem $e$ pontuação" características da televisão, com o objetivo de oferecer um conteúdo compatível com a audiência. O consumo de programas das famílias estava atrelado a temas domésticos, a ensinamentos morais e cidadãos e à educação infantil.

Uma vez determinada a audiência, é fácil a escolha do conteúdo do programa, o qual terá de forçosamente enquadrar-se nos quatro tipos básicos: recreação, propaganda, informação ou ensino, ou combinar dois ou mais desses tipos. A forma depende, todavia, de elementos especiais, que são condicionados, de um lado, pela madureza do conteúdo, e do outro, pelos recursos disponíveis para a realização do programa. (...) A característica dominante desses programas é o impacto decorrente da realidade imediata. $\mathrm{O}$ valor educativo existirá na razão direta da seleção das tomadas ou cenas e nos comentários feitos a respeito das mesmas. (PAIVA e SOUZA, 1970, p. 440)

A audiência, nessa perspectiva, também assume o objetivo central da radiodifusão educativa, que tem a pretensão de conciliar o telespectador doméstico comum com um público alvo específico formado por telealunos. O telealuno poderia ser o jovem e adulto em busca de alfabetização e certificação do curso primário; ou os próprios profissionais da educação interessados na complementação e especialização profissional.

A audiência da televisão educativa do Instituto foi pensada para ser diversificada, compreendendo o contexto cultural do telealuno. Era preciso produzir uma programação capaz de contemplar o aluno em busca de alfabetização e o aluno em busca de especialização (formação de professores). O contexto cultural em que essas audiências estão inseridas e as representações que lhes são atribuídas no âmbito das políticas educacionais são distintas. De 
acordo com Oliveira (1999), o aluno no âmbito da educação de jovens e adultos, não é o estudante universitário ou o profissional qualificado que busca formação continuada ou especialização. Ele geralmente é oriundo das classes populares, criado em ambientes com pouca ou nenhuma experiência com a educação formal, escolarizada. A proposta do Instituto era arrojada para a época porque propunha uma convergência entre a linguagem pedagógica e a linguagem da televisão. $\mathrm{O}$ argumento consistia em propor uma programação televisiva com conteúdos culturais considerados relevantes para a escolarização, mas que deveriam ser tratados pedagogicamente considerando a necessidade de também serem recreativos, de serem agradáveis para o telespectador e para o telealuno. Satisfazer a audiência tradicional da televisão, acostumada ao entretenimento fácil, era um dos objetivos. Mas, a inserção dos conteúdos educativos do currículo escolar encontrava resistência do telespectador. Era preciso criar a conscientização da necessidade da escolarização para o desenvolvimento da sociedade, para o melhor acesso ao mercado de trabalho formal e para garantir o bem estar social.

A educação pela escolarização, ou pela certificação de conclusão de curso, assumiu contornos de estratégia para o desenvolvimento humano, social e econômico defendido por instituições internacionais como a UNESCO, que propunha o uso dos veículos de massa como agentes de transformação social. O Instituto de Educação do Estado da Guanabara se destacou como pioneiro na formação de professores e profissionais para a televisão educativa, compreendendo-a como um instrumento fundamental para a criação de uma sociedade moderna, industrializada e educada a partir de concepções de progresso internacionais.

\section{APERFEIÇOAMENTO DO MAGISTÉRIO COM A TELEVISÃO}

O Instituto de Educação do Estado da Guanabara preparou um currículo para a formação continuada pela televisão nas primeiras turmas dos cursos de formação para a televisão educativa, que ocorreram em 1967, visando a realização de programas para a "Formação e Aperfeiçoamento do Magistério Primário"8. Os títulos dos programas eram: Um Retrato (Perfil profissional do professor), É Falando Que a Gente se Entende (Psicologia da infância e desenvolvimento da linguagem), Contando Histórias (Didática das Ciências Sociais), A Grande Corrida (Ciências Sociais Econômicas: Expansão Demográfica e Ensino), Uma Criança é uma Criança (Psicologia da Infância), Ouvidos e Olhos Juntos (Didática Geral - Posição dos Auxiliares Audiovisuais no 
Ensino), Este Mundo Maravilhoso (Didática das Ciências), Olhos para Ver (Didática das Ciências), Todos Juntos Podem Mais (Valor da Cooperação na Vida Escolar), Para Além destas Paredes (A Escola e a Comunidade), Noções de Radiciação (Matemática- Prof. Paulo Viveiros), Extração de Rair Quadrada (Matemática- Prof. Roberto Cato), Ensinando a Ver (Artes Plásticas - Prof. Ivaldo Ribeiro Branco).

Esses programas apresentavam conteúdos específicos para os alunos do curso normal e foram idealizados para serem exibidos no circuito interno de televisão educativa da instituição. No ano seguinte, 1968, alguns jornais ${ }^{9}$ noticiaram a inscrição para um estágio de produção em televisão educativa para a realização de 50 programas de televisão que comporiam o curso Formação e Aperfeiçoamento do Magistério Primário, feito no Instituto de Educação do Estado da Guanabara. Não encontramos informações precisas sobre a distribuição e exibição destes programas em sistemas abertos ou fechados de televisão. Porém, essa iniciativa gerou o projeto de tele-educação chamado S.O.S! Precisa-se de Professor, que era dividido a partir de fundamentos de psicologia da aprendizagem, de princípios gerais de metodologia e motivação geral. Desta forma, o curso foi elaborado em seis desdobramentos de motivação:

1. Mãos que carregam o mundo - O Mestre.

2. Um pesado fardo leve - O Aluno.

3. A herança da humanidade - A Matéria.

4. Em busca de rumos - O método.

5. Dentro de quatro paredes - A Escola.

6. O futuro no presente - Os Fins da Educação.

Neste período, no Estado da Guanabara, havia grande necessidade de formação de professores e o Instituto de Educação era a principal escola normal do Estado da Guanabara. Contudo, a áurea dos anos dourados de 1950 não tinha o mesmo brilho. Segundo Lopes (2006) na contramão do que é admitido no senso comum, os anos de 1950 marcaram a primeira crise no Instituto de Educação. O motivo foi a necessidade de formar um número maior de professores para atender o aumento da demanda no ensino primário e o aumento das vagas por motivos eleitoreiros, que superlotaram as turmas do Instituto de Educação do Estado da Guanabara. O excesso de alunos descaracterizou o espaço físico. Salas de trabalho especializado foram transformadas em salas comuns, laboratórios foram desativados, e surgiram os primeiros registros de baixo rendimento em concursos de seleção. $\mathrm{Na}$ década seguinte, alguns profissionais da educação 
ainda desfrutaram do prestígio social da instituição, que no ano de 1968 formou a última turma a ter ingresso automático nos quadros do magistério do Estado da Guanabara. A qualidade e a excelência na educação, devido ao caráter de escola-laboratório, ainda estavam no imaginário das pessoas, e o Instituto precisava reconstruir de fato a qualidade educacional assumindo o pioneirismo em atividades experimentais e inovadoras no setor pedagógico.

O investimento em tele-educação foi uma estratégia adotada para aumentar a influência da instituição, como se pode observar na definição dos objetivos ${ }^{10}$ do circuito fechado de televisão educativa que, entre outras propostas, visava à ampliação da área de influência pedagógica do Instituto, dando-lhe destaque na atualização das técnicas de didática, na de divulgação científica e cultural, na orientação vocacional e na promoção socioeconômica e cultural do povo; e participação direta na reformulação dos padrões de televisão comercial da Guanabara, exercendo influência esclarecida e bem orientada na elaboração de programas culturais e artísticos das emissoras comerciais. Objetivos que foram definidos no anuário da Instituição, no ano de 1968.

A partir dos anos de 1970, a massificação do ensino, a demanda da população por proteção social e o processo de globalização crescente, colocam-se à frente da educação, mudando toda a organização do trabalho pedagógico e também do trabalho docente. Como Esteves (1995) explica: "a passagem de um sistema de ensino de elite para um sistema de ensino de massas implica um aumento quantitativo de professores e alunos, mas também o aparecimento de novos problemas qualitativos, que exigem uma reflexão profunda" (p. 96). Ensinar para grupos de crianças homogeneizadas pela seleção social, cultural e econômica, como as tradicionalmente matriculadas nas séries iniciais do Instituto de Educação, não representava a realidade dos novos quadros de alunos do Estado da Guanabara. A massificação da educação implicou na busca de alternativas para o atendimento dessas novas demandas, e consequentemente, na preparação do professores para novos métodos de aprendizagem capazes de suprir e dialogar com as diferenças socioeconômicas e culturais dos alunos. Desta forma, a ampliação da área de influência do Instituto de Educação do Estado da Guanabara, destacou o trabalho no desenvolvimento de uma linguagem educativa na televisão, como proposta de atualização das técnicas de didática com a intensificação do uso do audiovisual no ensino formal e não formal.

Quando nos grandes centros do País, o ensino direto dispuser de número suficiente de professores para atendimento de todos os alunos, então certamente, podemos ter a televisão numa atuação complementar, integrando e enriquecendo as atividades de classe. É o que ocorre na França, Inglaterra, Estados Unidos 
e tantos outros países. (...) No Brasil, no entanto, o que atualmente ocorre, no ensino pela TV, é a substituição, na maioria das vezes, de professores por monitores, junto aos alunos, por serem aqueles, ainda, em número deficitário.

De qualquer modo, o que a televisão tem realizado, nos países em desenvolvimento, caracteriza plenamente o seu papel na educação das massas e no aprimoramento do ensino. (SOUZA, 1970, p. 287)

Durante o período pesquisado, cerca de 250 professores se inscreveram nos cursos do Instituto, segundo dados contidos em documentos que podem ser encontrados no Centro de Memória do Instituto de Educação do Rio de Janeiro. Porém, as informações obtidas nos jornais da época, indicam que o número de profissionais formados nos curso do Instituto era maior. Nos primeiros anos, foi oferecido apenas o Curso Introdução à TV Educativa (80h ou 112h). No início dos anos de 1970, os cursos se diversificaram: Preparação para a TV Educativa (54h ou 60h), Comunicação de Massa e Educação pela TV (60h), Comunicação e Expressão através da TVE (60h), Técnica Operacional - manuseio de equipamentos e producãa de programas em estúdio e externas (teórico-prático, 60h e estágio de 48h). Estes cursos eram compostos com turmas que variavam entre 17 e 115 alunos inscritos.

\section{FIGURA 1}

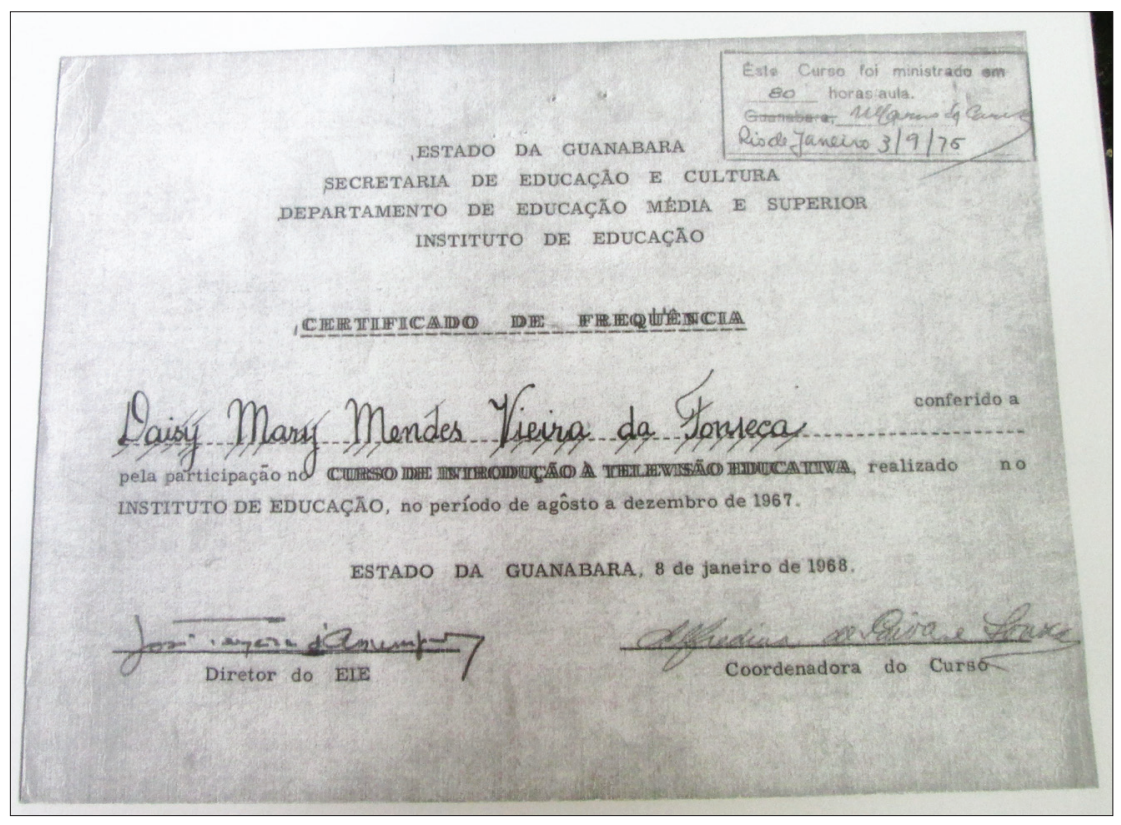

1 - Certificado de Conclusão de Curso Introdução à Televisão Educativa emitido pelo Instituto de Educação do Estado da Guanabara (1968) - Arquivo da Instituição (CEMI). 
Em documento sobre a abertura do Curso de Preparação para Televisão Educativa, datado de 20 de abril de 1970 e assinado pelo diretor geral do Instituto, José Teixeira de Assumpção, encontramos os critérios de seleção dos professores. A prioridade eram para os catedráticos do EIE, depois para os professores lotados no Instituto de Educação e nas escolas normais oficiais, seguido de professores de escolas normais particulares, professores do ensino superior, médio e primário do Estado da Guanabara, professores que exercessem funções no Estado da Guanabara e por último profissionais de áreas diversas interessados em televisão educativa. Os alunos deveriam pagar uma contribuição de $\mathrm{NCr} \$ 60,00$ correspondente ao material ilustrativo e apostilas. No ano seguinte, outro documento referente ao Curso de Preparação para Técnicos em Televisão Educativa, com duração de dois meses, pedia contribuição de $\operatorname{Cr} \$ 120,00$.

Em 1973, o Instituto de Educação ampliou a concepção de ensino para o uso da televisão com a modalidade Curso de TV Educativa integrada aos Estudos Adicionais, com atividades cujos temas eram: informações básicas sobre TV e sua utilização no contexto socioeconômico e cultural, e o despertar do interesse do professor em estudos adicionais para o valor da TV educativa como importante meio de comunicação de massa que interfere na capacidade de percepção e assimilação do aprendizado. O conteúdo das aulas era formado por conhecimentos sobre movimentos e planos de câmera para TV, iluminação, técnicas de produção, tipos de programas, roteiros e apresentação. No mesmo ano, iniciou-se o atendimento aos alunos da quinta série (a idade média dos alunos era de 10 a 12 anos), com objetivo de preencher o tempo livre com atividades consideradas construtivas. Eles aprendiam noções básicas de câmera, iluminação, uso do microfone para apresentação em TV, além de aulas de avaliação dos programas educativos das TVs comerciais e dos programas gravados pela TV educativa do Instituto. Nove turmas foram atendidas, totalizando 340 alunos.

O curso de formação para televisão educativa seguiu com o objetivo que alocava o professor como produtor de conteúdo, capacitado tecnicamente para trabalhar em estúdio de televisão. A mesma proposta foi apresentada aos alunos da quinta série com o propósito também de ensiná-los, a partir da ótica da TV educativa praticada no Instituto, a avaliar a programação da TV Comercial. Conhecer a técnica televisiva e as possibilidades dela era o caminho para ter uma visão crítica sobre o conteúdo veiculado. E, nesse ponto de vista, só quem domina os bastidores da televisão é capaz de não se deixar levar apenas pelo encantamento e entretenimento, mas absorver e ampliar as informações 
"relevantes" que são cunhadas nos ambientes educacionais e científicos e transformadas em informação e entretenimento.

A relevância da definição da proposta de televisão educativa praticada no Instituto de Educação parte da premissa que existem dois aspectos básicos e interligados ao formato televisivo quando nos referimos aos conteúdos educativos. O primeiro se configura em um plano geral que visa propagar conhecimentos que promovem práticas sociais, culturais e econômicas, é direcionado às grandes audiências, tem apelo comercial, busca também o entretenimento, mas foca em assuntos e temas importantes para o desenvolvimento humano e social das audiências. Já o segundo se estabelece pela necessidade de um planejamento que assegure a intencionalidade do caráter instrutivo do conteúdo apresentado na programação. Pode-se alcançar uma grande audiência, mas tem objetivos sólidos em relação a determinados públicos, como por exemplo, o formado por telealunos dos cursos de alfabetização e supletivo. A televisão educativa não estaria a serviço somente das massas de telespectadores porque deveria ter parte de sua programação direcionada a um público-alvo específico formado indispensavelmente por telealunos. O professor deveria estar à frente nesta proposta, guiando cada passo da produção. O professor e diretor do Instituto de Educação, nos anos de 1960 e 1970, escreveu o seguinte:

Muito potencial humano competente está a televisão educativa exigindo para o seu necessário desenvolvimento em nossa terra. Tais pessoas serão naturalmente os educadores que devem ser localizados e incentivados a conhecer o instrumento inestimável que é a TV.

Que papéis pode ou deve desempenhar o professor na TVE? Ainda não se fez estudo minucioso a respeito, mas do extremo da não existência de educador qualificado num programa chamado educativo até uma equipe composta toda ela de professores, tanto mais certos estaremos quanto mais próximos desta posição estivermos.

Que extraordinário operador de audição seria um professor de música; que magnífico cortador na encenação de uma peça teatral seria um professor de arte dramática; que perfeita apresentadora seria uma professora de canto desde que, todos, evidentemente, se tivessem preparado para essa atuação. Mas, acima de tais funções, que não seriam desempenhadas obrigatoriamente por professores, parece-nos necessário que sejam realmente professores o diretor da emissora, os diretores de programação e de produção, os produtores, os diretores e o apresentador. (ASSUNÇÃO, 1970, p. 279)

O posicionamento revela que a televisão educativa deveria ser gerida por educadores, que com a formação adequada também seriam diretores e produtores dos conteúdos educativos. A formação pretendida no Instituto ampliava o espaço de atuação do professor que estava restrito à sala de aula. A tecnologia dos veículos de 
comunicação de massa e a educação passaram a ser também uma temática relevante de discussão na formação do professor que, nesta perspectiva, entrava na disputa por espaço de trabalho no mercado de radiodifusão educativa. Os padrões de televisão educativa propostos pelo Instituto estavam de acordo com prerrogativas culturais e artísticas compatíveis a dos intelectuais do período, bem como ao modelo definido por eles como ideal de entretenimento construtivo na televisão. $\mathrm{O}$ entretenimento nessa perspectiva dialogava com os ideais de cultura do governo do Estado, responsável pela manutenção da estrutura da televisão da instituição.

O circuito de TV educativa do Instituto funcionou como um laboratório de experiências audiovisuais com professores, profissionais de televisão, técnicos e profissionais interessados no assunto. Inicialmente o público alvo eram professores, mas em pouco tempo, outros objetivos se tornaram também prioridade como: a formação de mão de obra para o corpo técnico das TVs estatais, a formação dos próprios alunos nos diferentes níveis escolares, a definição de uma linguagem para a televisão educativa no país.

O pensamento pedagógico disseminado pelo Instituto de Educação, tendo como figura central a professora Alfredina de Paiva e Souza, foi o modelo seguido para a radiodifusão educativa da época, que em uma primeira análise, se apresentou como um conceito amplo de significados abrangendo as múltiplas possibilidades educativas que podiam se enquadrar na programação do rádio e da televisão. A definição do termo, na proposta de Paiva e Souza, consistia na presença de algumas características como: intencionalidade na ação formativa; adequação ao nível de audiência; inserção em um planejamento global; previsão dos efeitos a atingir; e condição para avaliar esses efeitos. Esse conjunto de requisitos estava diretamente relacionado à audiência da programação, que seria avaliada pela quantidade de telespectadores e pela resposta dos mesmos na promoção de uma sociedade mais escolarizada e de acordo com os valores da época. Período caracterizado pela censura da ditadura civil-militar e pela valorização de aspectos morais da sociedade e de nacionalismo.

A formação desses profissionais foi organizada a partir da necessidade de se conhecer a técnica televisiva nos seus processos de produção para, assim traçar um planejamento didático e pedagógico adequado aos diferentes grupos que poderiam ser atingidos. Essa inserção dos audiovisuais na educação se integra às reformas do ensino básico implementadas nos anos de 1970 que privilegiava o modelo "tecnicista" ao considerar a eficiência do ensino como decorrente do uso correto e planejado de métodos técnicos e didáticos. 


\section{CONSIDERAÇÕES FINAIS}

Atualmente, a formação de professores para o uso da tecnologia em sala de aula e para a percepção da relevância dos meios de comunicação na vida do ser humano em diferentes aspectos (social, cultural e econômico) tem sido um tema debatido em todas as áreas da educação escolar e não escolar. Revisitar o curso de formação de professores do Instituto de Educação nos anos 1960 é um exercício importante para pensarmos os rumos que os estudos sobre educação e mídia seguem na história recente da televisão educativa no Brasil. Percebemos que a proposta de professor produtor de conteúdo de mídia educativa não é recente e que a sugestão de uma alfabetização midiática na escola e fora dela também era um questionamento no começo da TV educativa.

Ao observarmos a história da televisão brasileira, focalizando a programação educativa, encontramos algumas lacunas e percebemos que o preenchimento destas brechas é fundamental para ampliar conhecimentos no campo da história da educação no Brasil. Os espaços dos meios de comunicação são os grandes responsáveis pelos processos de sociabilidade e, em especial, como promotores do debate público sobre temas de interesse comum, entre eles a memória. A relação da educação com os meios de comunicação, geralmente, se coloca no tempo presente prevalecendo a ideia de que essa ligação é sempre atual. As experiências do passado não são lembradas e, algumas vezes, são apresentadas como novidade no campo educacional. A concepção de um profissional docente que agrega conhecimentos teóricos e técnicos de produção audiovisual não pode ser considerada uma necessidade do tempo presente, pautado na rapidez da veiculação de imagens e vídeos na Internet. Nas primeiras experiências com o vídeo, a formação de professores para o uso da televisão já estava associada ao papel de produtor. Ele deveria ser o responsável pela condução de todas as etapas de um programa de televisão.

No período analisado, a televisão estava no auge da popularidade com uma programação estruturada com base no entretenimento dos programas de auditório, das gincanas, das telenovelas. O uso da televisão a serviço da educação, não era apenas uma solução para os governos e para os órgãos internacionais, mas era também uma aspiração social. A popularidade da televisão e as possibilidades técnicas do audiovisual, aliada à crítica sobre a baixa qualidade da programação das emissoras comerciais, fomentaram a defesa de programas mais educativos e instrutivos. Os profissionais da educação, então, reivindicaram apoiados no saber pedagógico, o pioneirismo nas experiências com tele-educação. O Instituto de Educação do Estado 
da Guanabara assumiu o papel de condutor de uma nova proposta de televisão que se colocava entre o modelo comercial e o modelo educativo praticado em emissoras de outros países.

A disputa entre pedagogos e profissionais de outras áreas por espaços na criação de materiais educativos como ferramentas educacionais em diferentes suportes de mídia não é uma novidade. Os suportes de tecnologia mudaram, mas as questões educacionais relativas ao uso dessas ferramentas na educação formal ou não formal continuam em debate. Debate que é fomentado pelas políticas educacionais, pela pressão econômica para a manutenção do crescimento da indústria de tecnologia, pela pressão social globalizada ávida por consumir informação e entretenimento.

A formação para a televisão iniciada no Instituto de Educação do Estado da Guanabara influenciou na construção de uma linguagem especifica para o audiovisual educativo brasileiro. Uma linguagem pedagógica que compreendia a importância do entretenimento como parte estrutural da programação televisiva. Contudo, em nossas análises, percebemos que o audiovisual educativo, praticado no Instituto, revestido com assuntos culturais ou no formato de cursos para a televisão, impôs o pedagógico como parte central da programação, relegando o entretenimento.

A criação da televisão educativa no Estado da Guanabara estava relacionada à política de ampliação de vagas escolares no Estado e à pressão de órgãos internacionais que apostavam na educação e na utilização dos meios de comunicação como formas de difundir um ideal de democracia e de direitos humanos e sociais que dialogassem com as práticas econômicas do sistema capitalista. Era uma interpretação de educação para o desenvolvimento das nações sustentada em ideais direcionados ao crescimento industrial e aos valores capitalistas. Os cursos de formação de professores para a televisão educativa do Instituto de Educação do Estado da Guanabara fortaleceram a participação de educadores e pedagogos no debate sobre os tipos de produtos culturais ou educativos que eram veiculados na TV.

\section{REFERÊNCIAS}

ASSUNÇÃO, J. T. Pedagogia e Produção para a TVE. Revista Brasileira de Estudos Pedagógicos, v.52, n. 116, out./dez., 1970.

BERGAMO, A. A reconfiguração do público. In: RIBEIRO, A. P.; SACRAMENTO, I.; ROXO, M. (org.). A História da Televisão no Brasil. São Paulo: Contexto, 2010.

BURKE, P. A nova história, seu passado e seu futuro. A escrita da história: novas perspectivas. São Paulo: UNESP, 1992. 
CAPELATO, M. H. R. Imprensa e a História do Brasil. São Paulo: Contexto/EDUSP, 1988.

CUNHA, L. A. Educação e Desenvolvimento Social no Brasil. Rio de Janeiro: Ed. Francisco Alves, 1975.

ESTEVES, J M. Mudanças sociais e função docente. In: NÓVOA, A (org.). Profissão professor.

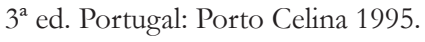

FRANCO, M. L. P.B. Análise de Conteúdo. $3^{\mathrm{a}}$ ed. Brasília: Líber Livro Editora, 2008.

JAMBEIRO, O.. A TV no Brasil do século XX. Editora da Universidade Federal da Bahia (EDUFBA), 2002.

LOPES, S. de C.. Oficina de mestres: História, memória e silêncio sobre a Escola de professores do Instituto de Educação do Rio de Janeiro (1932-1939). Rio de Janeiro: DP\&A, 2006.

NETTO, J. P. Pequena história da ditadura militar brasileira (1964-1985). São Paulo: Cortez, 2014.

OLIVEIRA, M. K. de. Jovens e adultos como sujeitos de conhecimento e aprendizagem. Rev. Bras. Educ., Rio de Janeiro, n. 12, dez. 1999.

OROZCO GÓMEZ, G. Television, audiências y educacion. Buenos

Aires: Norma Editorial, 2001.

PAIVA E SOUZA, A. de. Pedagogia e Produção dos Programas da RTV Educativa. Revista Brasileira de Estudos Pedagógicos, v.52, n. 116, out./dez.,1970.

PRIOLLI, G. A tela pequena no Brasil grande: anos 50: o patrocinador faz o show. In: LIMA, F. B.; PRIOLLI, G.; MACHADO, A. Televisão e vídeo. Rio de Janeiro: Jorge Zahar Editor, 1985. RIBEIRO, A. P. G.; SACRAMENTO, I. A Renovação Estética da TV. In: RIBEIRO, A. P.; SACRAMENTO, I.; ROXO, M. (org.). História da televisão no Brasil. São Paulo: Contexto, 2010. SOUZA, J. B. de P. Preparação de Professores para a TV Educativa. Revista Brasileira de Estudos Pedagógicos, v.52, n. 116, out./dez.,1970

\section{NOTAS}

${ }^{1}$ Os Diários Associados eram estruturados por várias empresas de comunicação, formando um conglomerado jornalístico bastante influente. No período em que a TV foi inaugurada o grupo detinha o controle de veículos de comunicação como o jornal O Jornal (RJ), a revista O Cruzeiro, o jornal Última Hora, o jornal Diário da Noite (SP), o estúdio de cinema Tupã e as rádios Tupi, Difusora e Record.

${ }^{2}$ O Estado da Guanabara existiu durante o período de 1960 a 1975 no território que corresponde ao Estado do Rio de Janeiro. Optamos por manter o nome Instituto de Educação do Rio de Janeiro no título do trabalho porque o Estado da Guanabara foi extinto em março de 1975.

${ }^{3}$ João da Silva foi o primeiro curso supletivo usado no formato de telenovela direcionada ao ensino primário, iniciando um modelo de tele-educação cujos alicerces estavam ancorados na educação formal com certificação aos alunos/telespectadores que se submetiam a processo de avaliação para conclusão referente às quatro séries iniciais do antigo primeiro grau do curso primário. Ainda hoje, o formato televisivo de João da Silva é replicado e atualizado em programas de tele-educação apoiados pelo Ministério da Educação e Cultura (MEC). O enredo tem como personagem principal o jovem João da Silva que deixa sua cidade natal no interior para viver na "cidade grande". Ele era semianalfabeto e representava o típico nordestino que abandona sua condição de trabalhador rural para viver na capital enfrentando diferentes desafios: o desemprego, a desqualificação profissional, a falta de moradia, a alfabetização e a escolarização com a conclusão do ensino primário. 
${ }^{4}$ Seguindo uma análise fundamentada nos pressupostos da nova história, adotamos o termo ditadura civil-militar para tirar da invisibilidade e do esquecimento atores sociais que junto aos militares deram sustentação ao golpe de 1964 no Brasil. "O regime derivado do golpe do $1^{\circ}$ de abril sempre haverá de contar, ao longo da sua vigência, com a tutela militar; mas constitui um grave erro caracterizá-la tão somente como uma ditadura militar — se esta tutela é indiscutível, constituindo mesmo um de seus traços peculiares, é inegavelmente indiscutível que a ditadura instaurada no $1^{\circ}$ de abril foi o regime político que melhor atendia os interesses do grande capital: por isto, deve ser entendido como uma forma de autocracia burguesa (na interpretação de Florestan Fernandes) ou, ainda, como ditadura do grande capital (conforme a análise de Octávio Ianni)." (NETTO, 2014, p. 74)

${ }^{5}$ Fonte: Arquivo do CEMI.

${ }^{6}$ Foi um sistema útil para organizar a grade de horário sistematizando e aumentando a venda de espaço publicitário. (RIBEIRO \& SACRAMENTO, 2010)

${ }^{7} \mathrm{O}$ conceito de audiência do texto é definido por Orozco Gómez (2001) segundo o qual ser audiência significa deixar de ser identificado por parâmetros como idade, gênero, classe social, grau de escolaridade, atividade profissional para ser identificado a partir do que consome na programação televisiva ou outros veículos de comunicação. Para o autor, os limites tradicionais de diferenciação entre os grupos são superados em prol de uma segmentação midiática baseada em critérios transversais que enfatizam as subjetividades e modos de percepção para classificarem os sujeitos de acordo com o tipo de programa que veem na televisão.

${ }^{8}$ Fonte: Arquivo do CEMI.

${ }^{9}$ Fonte: Jornal do Brasil 23/04/68, Diário de Notícias, 24/04/1968.

${ }^{10}$ Fonte: Anuário da Instituição 1968 - Arquivo do CEMI.

Submetido: 02/06/2016

Aprovado: 29/08/2017

Contato: Pontifícia Universidade Católica do Rio de Janeiro (PUC-Rio.) Departamento de Educação Rua Marquês de São Vicente, 225 - Gávea Rio de Janeiro | RJ | Brasil CEP 22.453-900 